Research Paper

\title{
Theoretical study on the cooling procedure for vertical flow sinters
}

\author{
Lisheng Pan ${ }^{\mathrm{a}, *}$, Xiaolin Wei ${ }^{\mathrm{a}}$, Yan Peng ${ }^{\mathrm{b}}$, Yuejing $\mathrm{Ma}^{\mathrm{c}}$, Bo $\mathrm{Li}^{\mathrm{a}}$ \\ ${ }^{a}$ State Key Laboratory of High Temperature Gas Dynamics, Institute of Mechanics, Chinese Academy of Sciences, Beijing 100190, China \\ ${ }^{\mathrm{b}}$ Citic Heavy Industries Co., Ltd., Luoyang 471039, China \\ ${ }^{\mathrm{c}}$ School of Environment and Energy Engineering, Beijing University of Civil Engineering and Architecture, Beijing 100044, China
}

\section{H I G H L I G H T S}

- A theoretical model is developed for cooling procedure for vertical flow sinters.

- The model is reliable for predicting the operational parameters.

- The pressure drop and the heat transfer are studied for several conditions.

\section{A R T I C L E I N F O}

\section{Article history:}

Received 17 March 2017

Accepted 11 August 2017

Available online 12 August 2017

\section{Keywords:}

Vertical flow sinter cooling device

Sinter layer

Convection heat transfer

Pressure drop

\begin{abstract}
A B S T R A C T
Sinter cooling is an important process in the sinter production process. This article analyses the sinter cooling procedure in a new vertical cooling device. The analysis model is established to study the pressure drop and the heat transfer and is used to analyse several conditions. The results show that the analysis model is reliable for predicting the operational parameters and achieving the preliminary projected dimension. The parameters such as the cooling air temperature and the cooling air superficial velocity non-uniformly vary along the cooling device. When the cooling device diameter is set as an independent variable, the normal volumetric flow rate is not related to the cooling device diameter. The cooling time increases with the increase in cooling device diameter, whereas the sinter layer height is negatively correlated to the cooling device diameter. When the sinter flow rate is set as an independent variable instead of the cooling device diameter, the cooling time decreases, whereas the sinter layer height increases with the increasing sinter flow rate. Both cooling time and sinter layer height decrease with the increase in hot sinter temperature. Importantly, the pressure drop is minimal with variation of the hot sinter temperature.
\end{abstract}

() 2017 Elsevier Ltd. All rights reserved.

\section{Introduction}

The energy consumption of the sintering process accounts for $10-15 \%$ of the total iron and steel of energy consumption. It is extremely urgent to conserve energy in iron and steel because of the continuing tension for resources. From this viewpoint, increasingly more researchers are paying attention to the energy conservation and emission reduction to optimize the sintering process. The performance of the annular cooler, which is commonly used, affects the cooling efficiency, the reliability and the energy conservation. A huge amount of heat is recovered from the sinter cooling process and can be reversed to electrical energy.

Many experts and scholars have studied the cooling process of sinters using numerical simulations. The purpose is usually to opti-

\footnotetext{
* Corresponding author.

E-mail address: panlisheng@imech.ac.cn (L. Pan).
}

mize the operating parameters by investigating the flow and heat transfer of a sintering cooler bed. Caputo et al. [1] developed a simulation model for gas-solid beds that considered the thermal behaviour and the actual heat recovery of a sintering cooler bed for different design and operating parameters. Caputo et al. [2] also developed a two-dimensional time-dependent convectionconduction heat transfer model for cooling beds to optimize the size of the air capture hoods for heat recovery systems. Zhang et al. [3] developed a mathematical model for the sinter cooling process. Several parameters were analysed in the study: the size of the sinter, inlet velocity, material height, porosity and inlet temperature. The model results were consistent with the test data. Some researchers established three-dimensional models to simulate the flow, the heat transfer and the relevant parameters. Leong et al. [4] used the CFD (Computational Fluid Dynamic) method to investigate the different distributions of the sinter layer porosity that cause the temperature difference of the sinter cooler. Both 


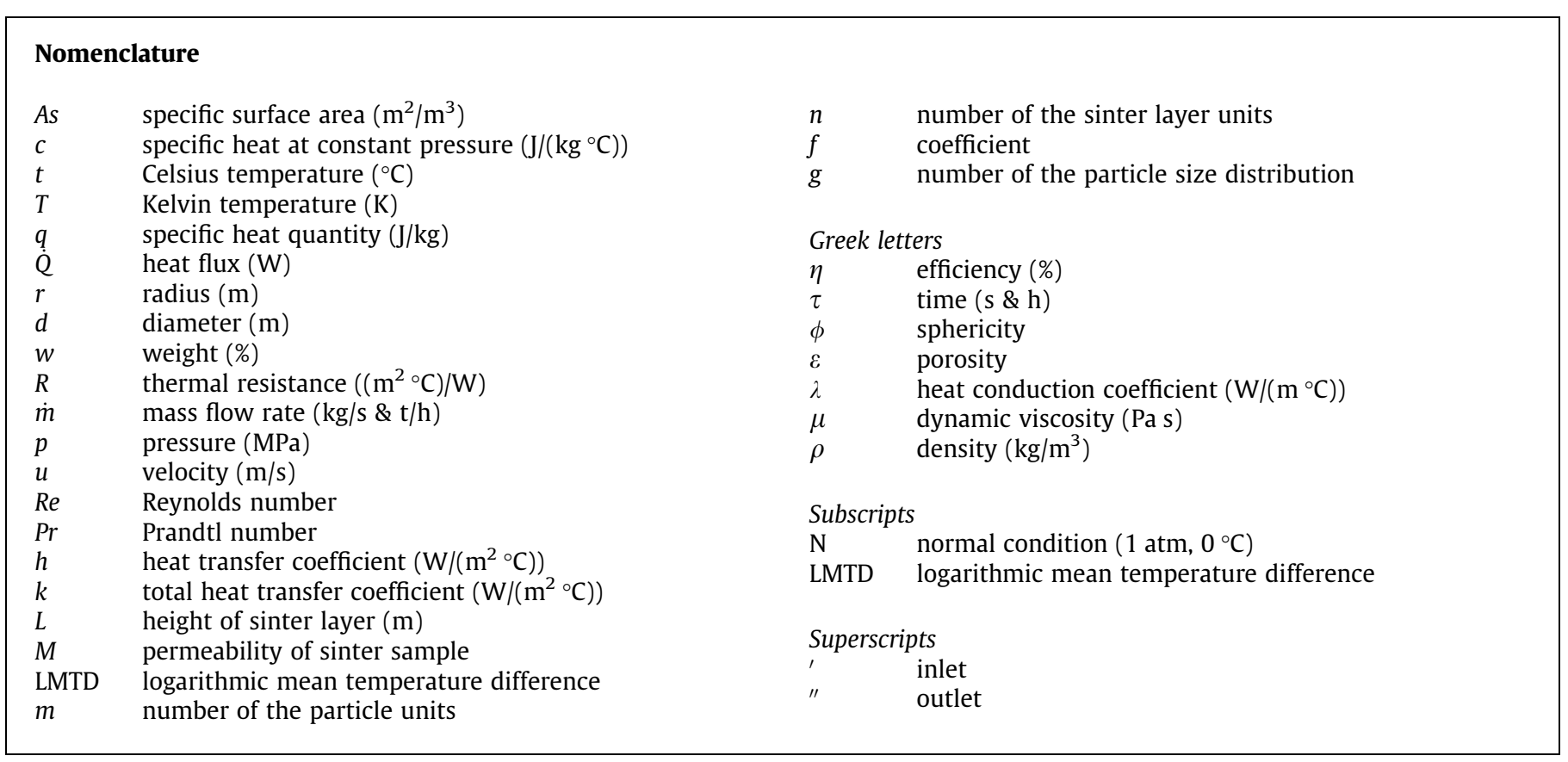

numerical and experimental methods were used in the study of Jang et al. [5]. The three-dimensional turbulent, transient fluid flow and heat transfer were analysed using a four-row packed sphere bed model. A correlation equation among the particle diameter, Reynolds number and Nusselt number was provided. Some experts and scholars studied the gas-solid heat transfer process in the different bed layers and found its heat transfer rules. Dong et al. [6] established a physical model to study the gas solid heat transfer process. The results demonstrated that the gas sinter ratio and bed layer depth significantly affected the variations of the sinter temperature, the gas outlet temperature and exergy value. Zhang et al. [7] established a mathematical model for the cooling process in a sinter circular cooler. In the optimizing study, several parameters such as the height and porosity were considered. Feng et al. [8] studied the basic law of the gas flow in a vertical tank using CFD and user defined functions (UDF). The results showed that the influencing factors of the gas flow field were the radial voidage distribution of the bed layer and the pre-stored segment diameter. The leakage of the sinter cooling system seriously affected the cooling system function and the waste heat recovery. Dong et al. [9] analysed the reason of the air leakage of the sintering cooling system and the mechanism that affects the waste heat recovery. Two control methods were proposed to decrease the leakage, reasonably set the total pressure of the cooling system and reduce the flow rate and total pressure of the draught fan.

However, conventional technology provides notably low efficiency in recovering the heat energy because of the air leakage in the system. To solve the problem, a new sinter cooling craft is designed, as shown in Fig. 1 [10]. Two parameters are important for the new craft design, namely, convection heat transfer coefficient and air pressure drop in the sinter layer. In this article, the convection heat transfer coefficient and air pressure drop in sinter layer are experimentally studied.

\section{Methodology}

\subsection{Particle size distribution}

The sinter particle size distribution is complex. There are differences in the particle size distribution among different steel plants.

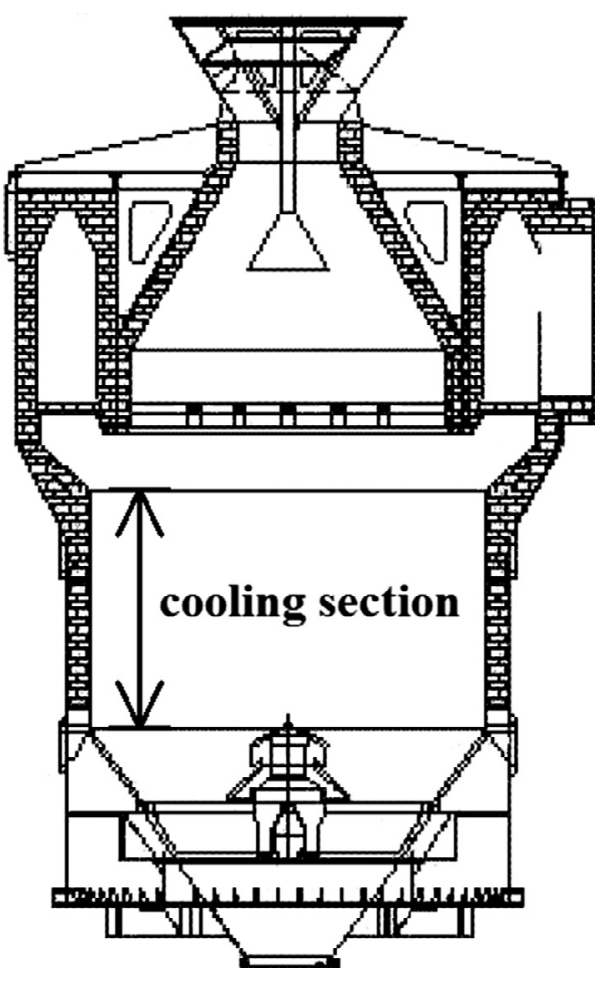

Fig. 1. Schematic diagram of the vertical flow sinter cooling device

In this article, the particle size distribution is specified as shown in Table 1 [11]. These data were derived from the measurement of a certain enterprise. An intermediate value of each range is used in the analysis. For example, $2.5 \mathrm{~mm}$ is used to replace the range of $0-5 \mathrm{~mm} ; 70 \mathrm{~mm}$ represents the range above $50 \mathrm{~mm}$.

\subsection{Properties and parameters}

In the cooling process, the hot sinter flows downward, whereas the cold air flows upward. The cold air removes the heat of the hot 
Table 1

Particle size distribution for the considered sinter.

\begin{tabular}{|c|c|c|c|c|c|c|}
\hline$d_{\text {sinter }}(\mathrm{m})$ & $\leq 0.005$ & $0.005-0.01$ & $0.01-0.02$ & $0.02-0.04$ & $0.04-0.05$ & $>0.050$ \\
\hline$w_{\text {quality }}(\%)$ & 8.45 & 12.54 & 37.78 & 24.67 & 6.98 & 9.58 \\
\hline
\end{tabular}

sinter, and the pressure drop occurs in the sinter layer. The air properties and sinter properties vary with temperature. Then, in the analysis, some air properties are obtained using the following equations. The sinter specific heat capacity is calculated using Eq. (5), which is deduced by Ref. [12]. Other properties are specified in Table 2.

$$
\begin{aligned}
C_{\text {air }}= & 1.0 \times 10^{3} \times\left(28.11+0.1967 \times 10^{-2} T_{\text {air }}\right. \\
& \left.+0.4802 \times 10^{-5} T_{\text {air }}^{2}-1.966 \times 10^{-9} T_{\text {air }}^{3}\right) / 28.97 \\
\rho_{\text {air }}= & 1.01325 \times 10^{-5} /\left(289 \times T_{\text {air }}\right) \\
\mu_{\text {air }}= & 1.711 \times 10^{-5} \times\left(T_{\text {air }} / 273\right)^{1.5} \times(273+122) /\left(T_{\text {air }}+122\right)
\end{aligned}
$$

$\lambda_{\text {air }}=2.72 \times 10^{-4} T_{\text {air }}^{0.8}$

$$
\begin{aligned}
c_{\text {sinter }}= & 1.0 \times 10^{3} \times\left(0.16+0.9221 \times 10^{-4} T_{\text {sinter }}\right. \\
& \left.-2.57 \times 10^{3} T_{\text {sinter }}^{-2}\right) \times 4.1868
\end{aligned}
$$

Some additional parameters are required before analysing the heat transfer and flow process in the vertical device, such as, cooling device diameter, cooling efficiency, sinter flow rate, sinter inlet temperature, sinter outlet temperature, cooling air inlet temperature and cooling air outlet temperature.

\subsection{Analysis method}

This article studied the heat transfer and the pressure drop in the sinter layer. Fig. 2 shows the flow chart to analyse the vertical flow sinter cooling. In the device, the temperature of the cooling air increases when it flows upward, whereas the temperature of the hot sinter decreases when it flows downward. Several properties of the air and the sinter are nonlinear with temperature. Therefore, the cooling procedure of the vertical flow sinter in the device is divided into many units to avoid introducing errors. The heat transfer and pressure drop in each sinter unit are orderly studied. Finally, the data for the entire device are obtained. According to the previous description, this unit can be named the layer unit.

There are two main heat transfer modes in the sinter layer: heat conduction in the sinter particle and convective heat transfer between sinter and air. There may also be heat transfer among the sinter particles or between the sinter and the inner wall of the device. However, the latter heat transfer is ignored because it is less important for the final results. Although the device is well insulated, heat loss from the device to the environment is unavoidable. The efficiency of the device can be expressed as

$\eta_{\text {device }}=\frac{\dot{Q}_{\text {air,get }}}{\dot{Q}_{\text {sinter,give }}}$

The sinter shape is approximately round like a ball. To simplify the problem, each sinter is considered a standard sphere. The sphere can be divided into many units: a small solid sphere and several hollow spheres, as shown in Fig. 3. These units are called particle units. Consequently, the heat conduction in the sphere is also divided into many micro procedures. For each hollow sphere, the thermal resistance can be expressed as [13]

$R_{\text {sinter }, \mathrm{i}}=\frac{1}{4 \pi \lambda_{\text {sinter }}} \cdot\left(\frac{1}{(i-1) \cdot \Delta r}-\frac{1}{i \cdot \Delta r}\right)$

For each hollow sphere, the temperature difference between the internal and the external walls is expressed in Eq. (8). All n-1 micro hollow spheres compose an entire hollow sphere. For the entire hollow sphere, the temperature difference is expressed in Eq. (9). Hence, Eq. (10) is obtained.

$\Delta t_{\text {sinter } \mathrm{i}}=\dot{Q}_{\text {sinter }, \mathrm{i}} \cdot R_{\text {sinter } \mathrm{i}}$

$\Delta t_{\text {sinter }}=\dot{Q}_{\text {sinter }} \cdot R_{\text {sinter }}$

$R_{\text {sinter }}=\sum_{i=2}^{m} \frac{\dot{Q}_{\text {sinter }, \mathrm{i}}}{\dot{Q}_{\text {sinter }}} \cdot R_{\text {sinter }, \mathrm{i}}$

In the heat transfer procedure, all heat comes from the hot sinter particle, which indicates that the heat flux through each hollow sphere is proportional to the volume of its wrapped solid sphere. From the above analysis, the thermal resistance of the entire sinter particle is expressed as

$R_{\text {sinter }}=\frac{1}{4 \pi \lambda_{\text {sinter }} \cdot r_{\text {sinter }}} \cdot \lim _{m \rightarrow \infty}\left\{\frac{1}{m^{2}} \cdot \sum_{i=2}^{m}\left[(i-0.5)^{3} \cdot\left(\frac{1}{i-1}-\frac{1}{i}\right)\right]\right\}$

It is worth noting that the thermal resistance of the micro solid sphere is not considered because the value tends to be infinity according to Eq. (7). However, if the number of the divided micro spheres is sufficiently large, the final result is sufficiently accurate. A larger number corresponds to a more accurate result.

The convective heat transfer in the sinter layer is calculated using Eq. (12) [14]. Reynolds number and Prandtl number in the equation are computed using Eqs. (13) and (14), respectively. Then, the convective heat transfer coefficient is obtained using Eq. (15). According to Eqs. (11) and (15), the total heat transfer coefficient is obtained using Eq. (16). It is worth noting that the parameters in the equations must correspond to the considered layer unit.

$$
\begin{aligned}
& N u=2+1.1 \operatorname{Pr}^{1 / 3} \operatorname{Re}^{0.6} \\
& \operatorname{Re}=\frac{u_{\mathrm{air}, \text { superficial }} \cdot d_{\text {sinter }} \cdot \rho_{\text {air }}}{\mu_{\mathrm{air}}}
\end{aligned}
$$

\begin{tabular}{|c|c|c|c|c|c|}
\hline Item & $\rho_{\mathrm{air}, \mathrm{N}}$ & $\varphi_{\text {sinter }}$ & $\rho_{\text {sinter,pile }}$ & $\lambda_{\text {sinter }}$ & $\varepsilon_{\text {sinter }}$ \\
\hline Unit & $\mathrm{kg} / \mathrm{m}^{3}$ & - & $\mathrm{kg} / \mathrm{m}^{3}$ & $\mathrm{~W} / \mathrm{m}^{\circ} \mathrm{C}$ & - \\
\hline Value & 1.293 & 0.85 & 1700 & 8.0 & 0.4 \\
\hline
\end{tabular}

$\operatorname{Pr}=\frac{c_{\text {air }} \cdot \mu_{\text {air }}}{\lambda_{\text {air }}}$

$h_{\text {convective }}=\frac{N u \cdot \lambda_{\text {air }}}{d_{\text {sinter }}}$

Table 2

Properties of the air and the sinter. 


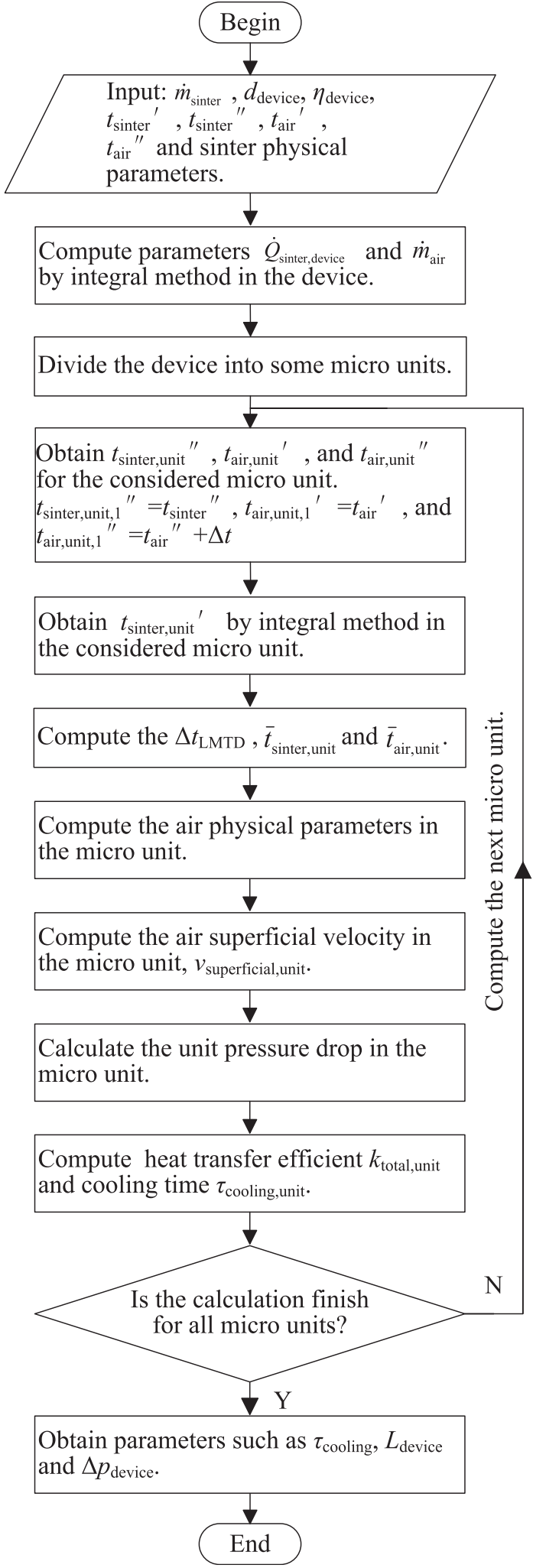

Fig. 2. Flow chart to analyse the vertical flow sinter cooling.

$k_{\text {total }}=\frac{1}{R_{\text {sinter }} \cdot\left(4 \pi r_{\text {sinter }}^{2}\right)+\frac{1}{h_{\text {convective }}}}$

As shown in Eqs. (11), (13), (15), and (16), the total heat transfer coefficient is related to the sinter particle size. However, there are six particle size ranges instead of a constant value. A model is pro-

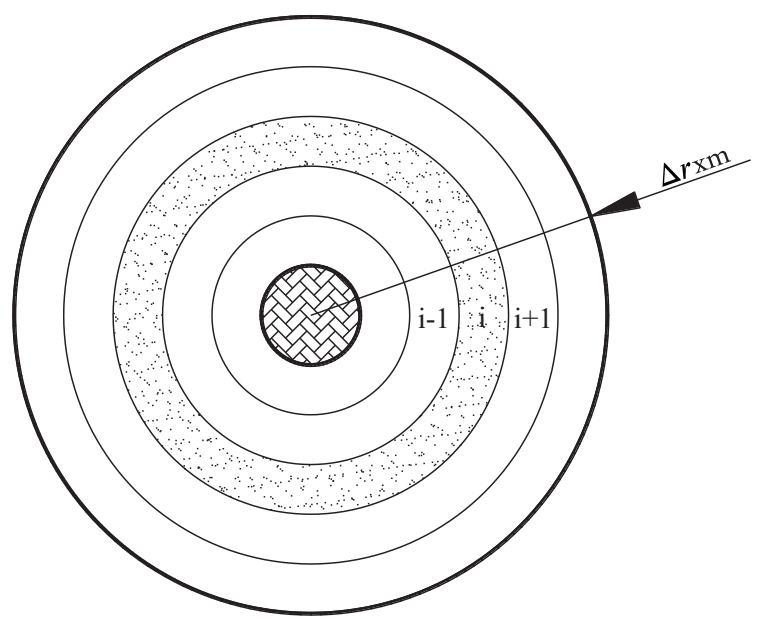

Fig. 3. Analysis model for a single sinter particle (particle units).

posed to study the heat transfer in the considered layer unit, as shown in Fig. 4. Each sinter group in the layer unit is arranged as a vertical column, and an intermediate value of each range represents the sinter group particles. For each sinter group, the logarithmic mean temperature difference (LMTD) and specific surface area are computed using Eqs. (17) and (18) [15], respectively.

$\Delta t_{\mathrm{LMTD}, \text { unit }}=\frac{\left(t_{\text {sinter,unit }}^{\prime}-t_{\text {air,unit }}^{\prime \prime}\right)-\left(t_{\text {sinter,unit }}^{\prime \prime}-t_{\text {air,unit }}^{\prime}\right)}{\ln \left[\left(t_{\text {sinter,unit }}^{\prime}-t_{\text {air,unit }}^{\prime \prime}\right) /\left(t_{\text {sinter,unit }}^{\prime \prime}-t_{\text {air,unit }}^{\prime}\right)\right]}$

$A s=\frac{6 \cdot(1-\varepsilon)}{d_{\text {sinter }}}$

For the layer unit, the sinter specific heat quantity is expressed in Eq. (19). In order to ensure the cooling effect, the maximum cooling time of all the particle sizes is selected as the unit cooling time, as shown in Eq. (20a). In this article, the sinter range number $n$ is equal to 6 . A coefficient is used considering the non-uniformity caused by the boundary effect. The non-uniformity coefficient is commonly used in the design calculation of the CDQ (Coke dry quenching) process. When the sinter flows downwards, the sinter layer becomes looser than the static situation. Then, the cooling air runs more smoothly and more quickly removes the heat. Therefore, a loose coefficient $f_{2}$ is introduced to consider this effect. In the analysis of the CDQ process, the loose coefficient is specified as 1.1 [16]. The volume weight should be used in the equation because it denotes the height percentage. In this article, the porosity and the pile density are considered constant, so the volume weight is replaced by the quality weight. Consequently, the height of the layer unit can be calculated according to Eq. (21). It is worth noting that the sinter layer is divided by the air temperature instead of the height. Therefore, the temperature drop is identical for each layer unit, while the height difference is inconsistent.

$$
\begin{aligned}
& q_{\text {sinter }}=t_{\text {sinter,unit }}^{\prime} c_{\text {sinter,unit }}^{\prime}-t_{\text {sinter,unit }}^{\prime \prime} c_{\text {sinter,unit }}^{\prime \prime} \\
& =\left(t_{\text {air,unit }}^{\prime \prime} c_{\text {air,unit }}^{\prime \prime}-t_{\text {air,unit }}^{\prime} c_{\text {air,unit }}^{\prime}\right) / \eta_{\text {device }} \\
& \tau_{\text {cooling,unit }}=\max \left\{f_{1} \cdot\left[\frac{q_{\text {sinter,unit }} \cdot w_{\text {quality }, \mathrm{j}} \cdot \rho_{\text {sinter,pile }} \cdot \eta_{\text {device }}}{f_{2} \cdot k_{\text {total } \mathrm{j}} \cdot A s_{\mathrm{j}} \cdot w_{\text {quality } \mathrm{j}} \cdot \Delta t_{\text {LMTD,unit }}}\right]\right\}_{\mathrm{j}=1,2, \cdots, \mathrm{g}} \\
& f_{2}=1.1
\end{aligned}
$$

$\tau_{\text {cooling,device }}=\sum_{i=1}^{n} \tau_{\text {cooling,unit, } \mathrm{i}}$

$L_{\text {unit }}=\frac{\tau_{\text {cooling,unit }} \cdot \dot{m}_{\text {sinter }}}{\rho_{\text {sinter,pile }} \cdot\left(\pi \cdot r_{\text {device }}^{2}\right)}$ 


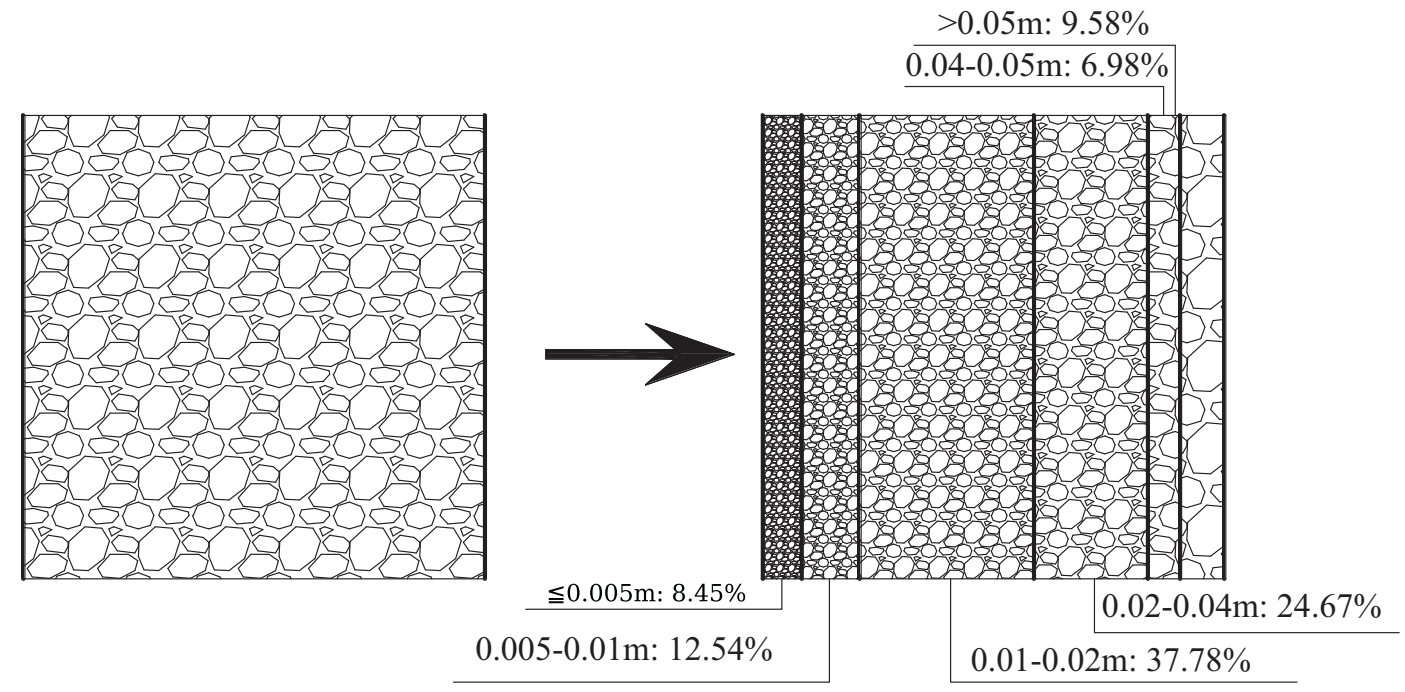

Fig. 4. Analysis model for the heat transfer of the sinter layer (vertical groups).

$L_{\text {device }}=\sum_{i=1}^{n} L_{\text {device, unit,i }}$

In the design calculation of the sinter ring cooler, a method is used to estimate the air pressure drop in the sinter layer [11]. The air pressure drop is expressed as

$\frac{\Delta p_{\text {drop }}}{L}=510 \cdot\left(u_{\text {air,superficial, }} / M\right)^{1.82}$

where $u_{\text {air,superficial,N }}$ is the air normal superficial velocity in the sinter layer, and $M$ is the permeability of the sinter layer. The term $M$ can indicate the sinter properties, and its value can be obtained from Fig. 5 with respect to the screening efficiency, which is measured using a sieve with a pore size of $12.7 \mathrm{~mm}$.

Ergun [17] proposed an empirical relation to calculate the pressure drop through a packed bed, as shown in Eq. (23).

$\frac{\Delta p_{\text {drop }}}{L}=g_{1} \frac{\left(1-\varepsilon_{\text {sinter }}\right)^{2} \mu_{\text {air }}}{\varepsilon_{\text {sinter }}^{3} d_{\text {sinter }}^{2}} u_{\text {air,superficial }}+g_{2} \frac{\left(1-\varepsilon_{\text {sinter }}\right)}{\varepsilon_{\text {sinter }}^{3} d_{\text {sinter }}} \rho_{\text {air }} u_{\text {air,superficial }}^{2}$

where $g_{1}=150$ and $g_{2}=1.75$. The equation is widely used to evaluate the pressure drop in a layer of uniform-sized particles. This equation is suitable for the particle layers with constant size.
However, the diameter of the considered sinter layer varies in a large range. To calculate the pressure drop of the sinter layer, an analysis model is proposed. As shown in Fig. 6, the entire layer unit is arranged as five horizontal groups according to the particle size. Then, the pressure gradient in each horizontal group is separately calculated, and the pressure gradient in the entire layer unit is obtained by adding the separate values with the weighted method, as shown in Eq. (24). The quality weight is used in the equation instead of the volume weight because of the reason in Eq. (20).

$\left(\frac{\Delta p_{\text {drop }}}{L}\right)_{\text {unit,i }}=\sum_{g=1}^{6}\left(\frac{\Delta p_{\text {drop }}}{L}\right)_{g} \cdot w_{\text {quality }, g}$

When the pressure gradient of each layer unit is obtained, the pressure drop in the entire sinter layer can be expressed as

$\Delta p_{\text {drop }}=\sum_{i=1}^{n}\left(\frac{\Delta p_{\text {drop }}}{L}\right)_{\text {unit,i }} \cdot L_{\text {unit,i }}$

\section{Results and discussion}

Using the aforementioned theoretical method, some important parameters are analysed. The variations of the heat transfer and

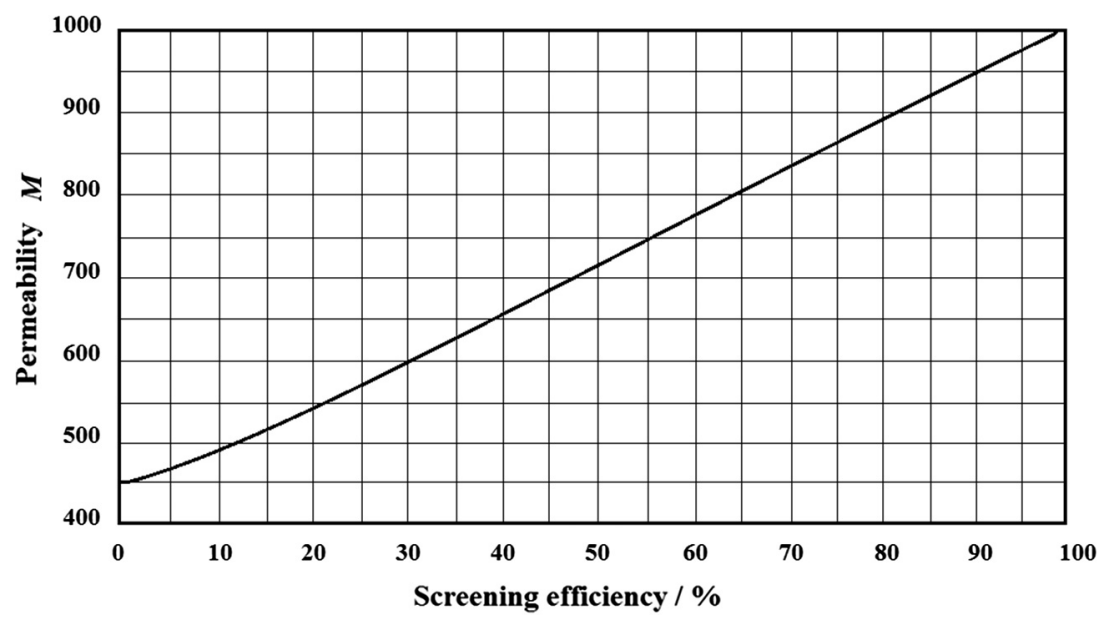

Fig. 5. Variation of the permeability with the screening efficiency. 

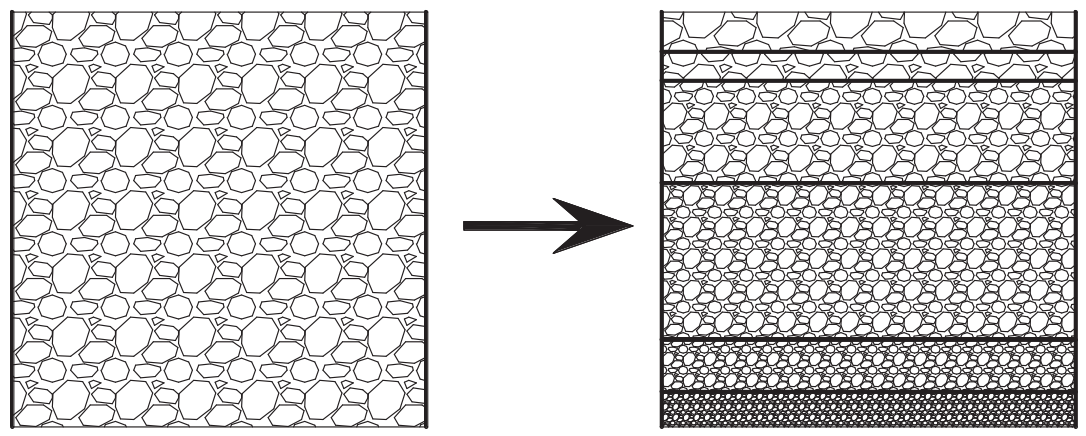

$>0.05 \mathrm{~m}: 9.58 \%$

$0.04-0.05 \mathrm{~m}: 6.98 \%$

$0.02-0.04 \mathrm{~m}: 24.67 \%$

$0.01-0.02 \mathrm{~m}: 37.78 \%$

$0.005-0.01 \mathrm{~m}: 12.54 \%$

$\leqq 0.005 \mathrm{~m}: 8.45 \%$

Fig. 6. Analysis model of the pressure drop for the sinter layer (horizontal groups).

Table 3

Parameters specified for analyzing the heat transfer and flow parameters.

\begin{tabular}{|c|c|c|c|c|c|c|c|}
\hline $\begin{array}{l}\text { Item } \\
\text { Unit }\end{array}$ & $\begin{array}{l}d_{\text {device }} \\
\mathrm{m}\end{array}$ & $\begin{array}{l}\eta_{\text {device }} \\
\%\end{array}$ & $\begin{array}{l}\dot{m}_{\text {sinter }} \\
\mathrm{t} / \mathrm{h}\end{array}$ & $\begin{array}{l}t_{\text {sinter }}^{\prime} \\
{ }^{\circ} \mathrm{C}\end{array}$ & $\begin{array}{l}t_{\text {sinter }}^{\prime \prime} \\
{ }^{\circ} \mathrm{C}\end{array}$ & $\begin{array}{l}t_{\mathrm{air}}^{\prime} \\
{ }^{\circ} \mathrm{C}\end{array}$ & $\begin{array}{l}t_{\mathrm{air}}^{\prime \prime} \\
{ }^{\circ} \mathrm{C}\end{array}$ \\
\hline Value & 10 & 95 & 400 & 750 & 200 & 100 & 600 \\
\hline
\end{tabular}

the air flow parameters along the cooling device are shown in this chapter. The relationship of the parameters is also obtained.

\subsection{Heat transfer and flow parameters in the cooling device}

In the theoretical study, the cooling device is divided into several units considering the variation of the parameters along the

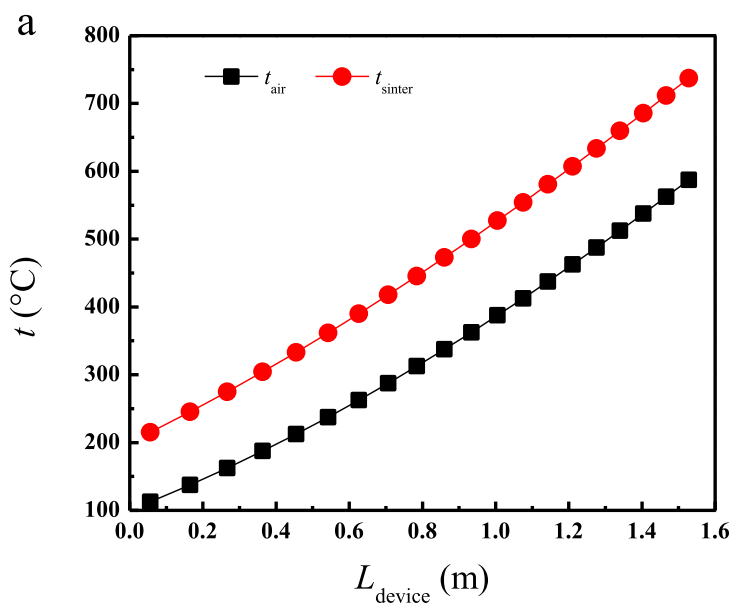

cooling device. Then, the analysis can provide more accurate results than taking it for granted that the heat transfer and the flow are identical in the entire cooling device. In this section, all operating parameters are specified, as shown in Table 3. The heat transfer and the flow situation are studied along the cooling device height.

Fig. 7a shows the temperature of the sinter and the cooling air. Because the properties of the sinter and the air vary with
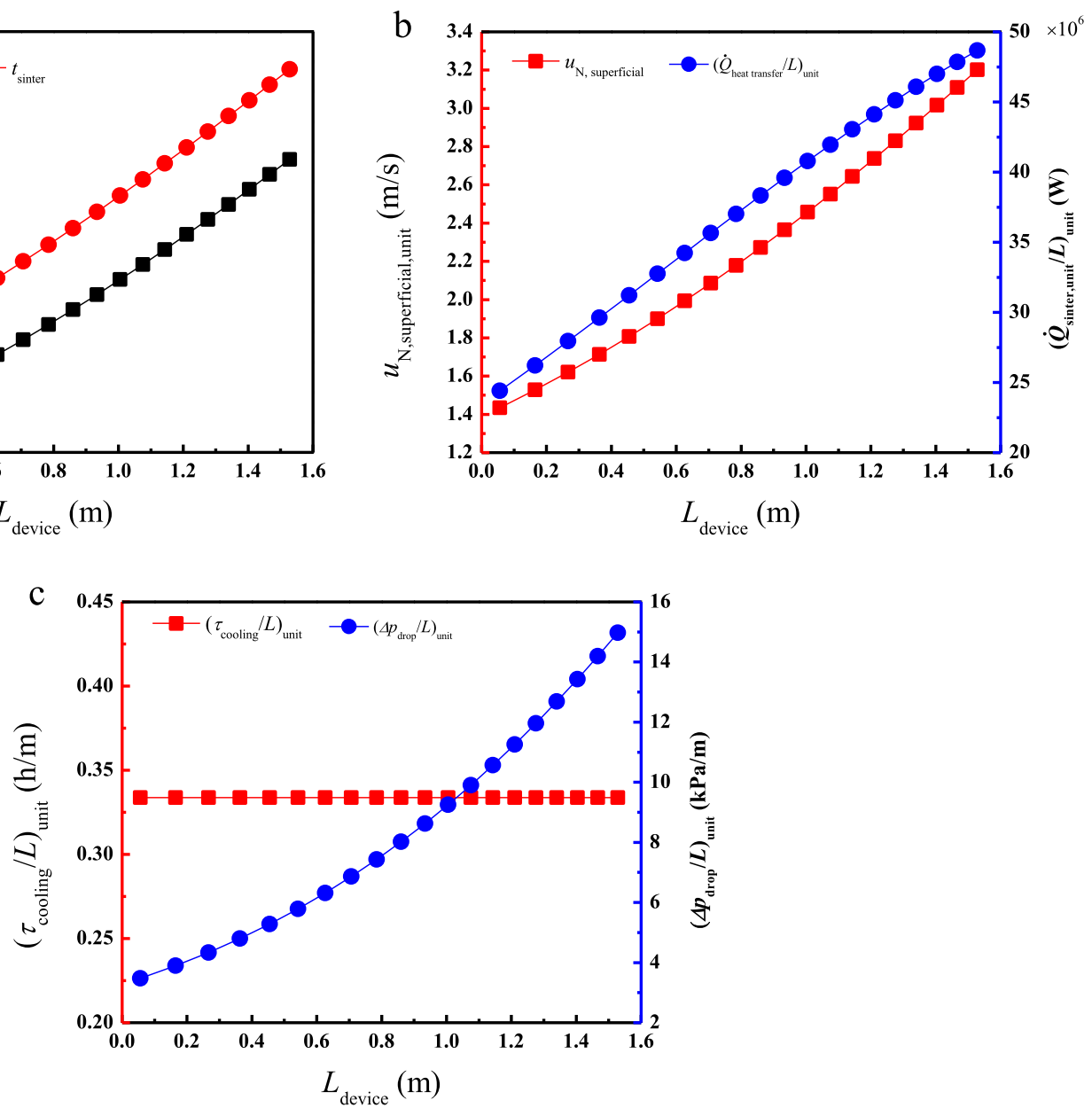

Fig. 7. Variation of the heat transfer and air flow parameters along the cooling device: (a) temperature of the sinter and cooling air; (b) air normal superficial velocity and heat flux; (c) cooling time and pressure drop. 
Table 4

Parameters specified for analyzing the cooling device diameter effect.

\begin{tabular}{|c|c|c|c|c|c|c|c|}
\hline Item & $d_{\text {device }}$ & $\eta_{\text {device }}$ & $\dot{m}_{\text {sinter }}$ & $t_{\text {sinter }}^{\prime}$ & $t_{\text {sinter }}^{\prime \prime}$ & $t_{\mathrm{air}}^{\prime}$ & $t_{\mathrm{air}}^{\prime \prime}$ \\
\hline Unit & $\mathrm{m}$ & $\%$ & $\mathrm{t} / \mathrm{h}$ & ${ }^{\circ} \mathrm{C}$ & ${ }^{\circ} \mathrm{C}$ & ${ }^{\circ} \mathrm{C}$ & ${ }^{\circ} \mathrm{C}$ \\
\hline Value & $8-11$ & 95 & 400 & 700 & 200 & $20-180$ & 600 \\
\hline
\end{tabular}

temperature along the cooling device, the temperature lines are not straight. This phenomenon will be neglected if it is only studied with the entire cooling device. As shown in Fig. 7b, the air normal superficial velocity increases along the cooling device height. In the upper part of the cooling device, the temperature is higher. The high temperature indicates a low density. With a constant flow rate of the cooling air, the normal superficial velocity increases with decreasing the density. The sinter has a higher heat quantity at a higher temperature. Therefore, the specific heat flux also increases along the cooling device. The sinter specific heat flux and the convective heat transfer coefficient in each unit affect the cooling time. Both factors vary along the cooling device, whereas the specific cooling time maintains the constants throughout the cooling device, as shown in Fig. 7c because the cooling time is directly proportional to the height of the sinter layer, as indicated in Eq. (21a). The specific pressure drop is positively related to the air normal superficial velocity according to Eq. (23). With the constant specific cooling time, the specific pressure drop increases along the cooling device height.
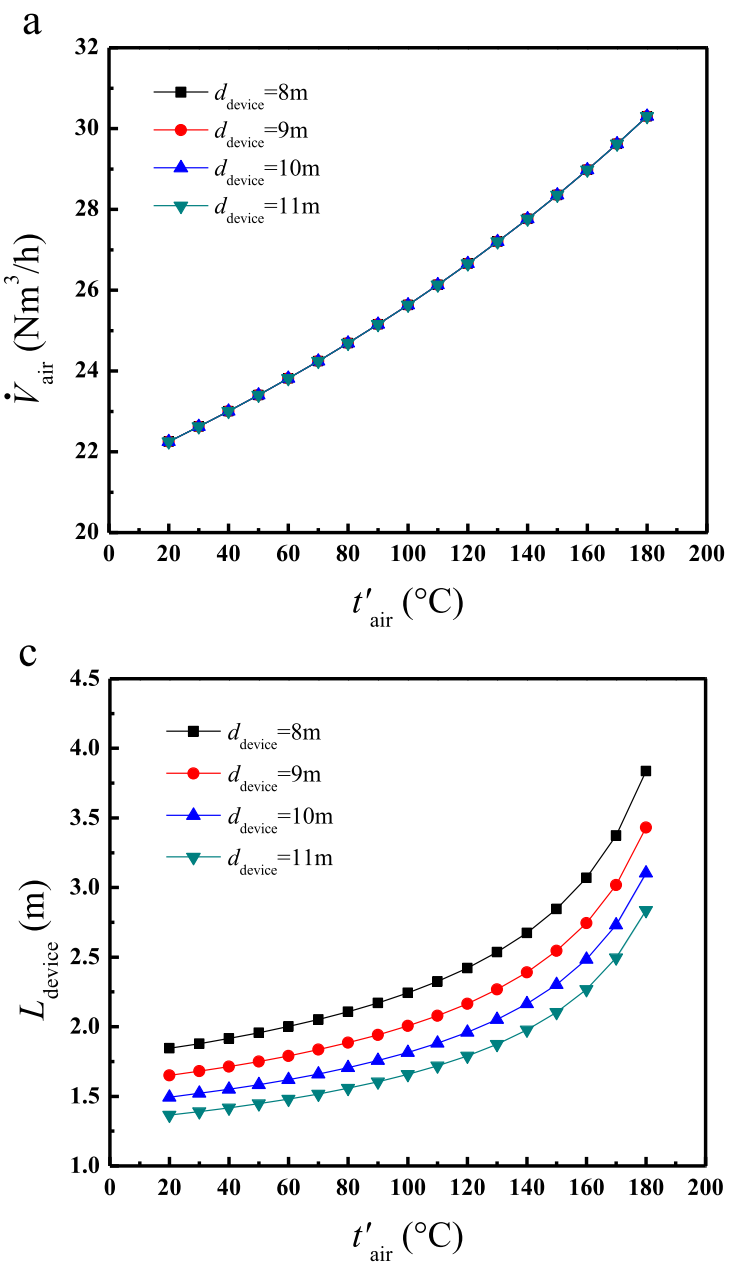

\subsection{Effect of the cooling device diameter}

This section studies the effect of the cooling device diameter and the cooling air temperature on the other device parameters, namely, the cooling air flow rate, the cooling time, the device height and the pressure drop. Table 4 shows the specified parameters. The range of the cooling device diameter is from 8 to $11 \mathrm{~m}$. The coldest cooling air considered is specified as $20^{\circ} \mathrm{C}$ to imitate total nature air, whereas the hotter cooling air is used to imitate the circulating cooling air from the waste heat boiler.

The cooling air flow rate is related to the cooling air import and export parameters, the sinter import and export parameters and the sinter flow rate. In the analysis, the sinter flow rate remains at $400 \mathrm{t} / \mathrm{h}$, and the sinter import and export temperature are constant, so the heat quantity has a unique value in this section. In addition, the cooling air outlet temperature also remains constant. Therefore, the normal volumetric flow rate increases with the increase in cooling air temperature but is not related to the cooling device diameter, as shown in Fig. 8a. The increase in cooling air

b

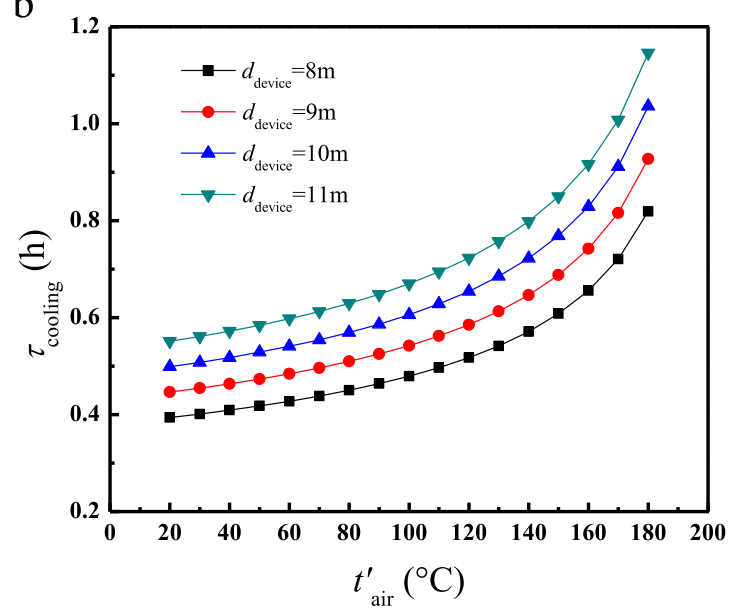

d

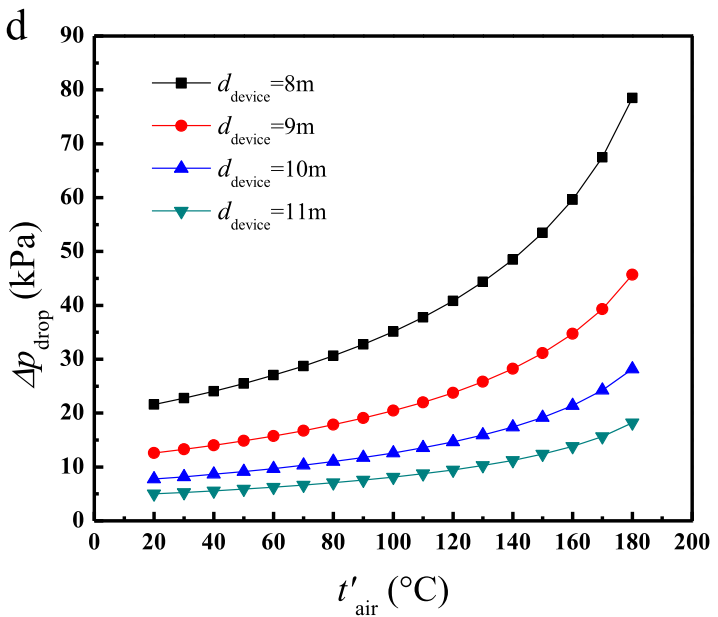

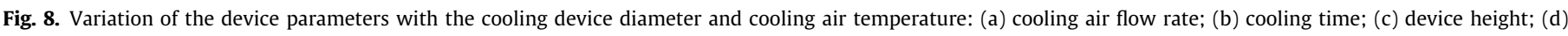
pressure drop. 
Table 5

Parameters for analyzing the sinter flow rate influence.

\begin{tabular}{|c|c|c|c|c|c|c|c|}
\hline $\begin{array}{l}\text { Item } \\
\text { Unit }\end{array}$ & $\begin{array}{l}d_{\text {device }} \\
\mathrm{m}\end{array}$ & $\begin{array}{l}\eta_{\text {device }} \\
\%\end{array}$ & $\begin{array}{l}\dot{m}_{\text {sinter }} \\
\mathrm{t} / \mathrm{h}\end{array}$ & $\begin{array}{l}t_{\text {sinter }}^{\prime} \\
{ }^{\circ} \mathrm{C}\end{array}$ & $\begin{array}{l}t_{\text {sinter }}^{\prime \prime} \\
{ }^{\circ} \mathrm{C}\end{array}$ & $\begin{array}{l}t_{\text {air }}^{\prime} \\
{ }^{\circ} \mathrm{C}\end{array}$ & $\begin{array}{l}t_{\text {air }}^{\prime \prime} \\
{ }^{\circ} \mathrm{C}\end{array}$ \\
\hline Value & 10 & 95 & $300-500$ & 700 & 200 & $20-180$ & 600 \\
\hline
\end{tabular}

flow rate helps enhance the convective heat transfer coefficient according to Eqs. (12) and (13). Additionally, the mean air parameters in the entire cooling device, namely, specific heat capacity, density and heat conduction coefficient, lightly vary with the variation in cooling air temperature. However, the logarithmic mean temperature difference dominates the cooling time, compared with the convective heat transfer coefficient and the mean air parameters. The logarithmic mean temperature difference decreases rapidly with the cooling air inlet temperature, which causes the rapid increase in cooling time, as shown in Fig. 8b. Fig. 8 also shows that the cooling time increases with the increase in cooling device diameter because the cooling air normal superficial velocity and the convective heat transfer coefficient significantly decrease when the cooling device diameter increases. The low convective heat transfer coefficient leads to a high cooling time, which is indicated in Eq. (20).

As shown in Eq. (21), the sinter layer height is determined only by the cooling time and cooling device diameter with constant sinter mass flow rate and sinter pile density. Consequently, the trend of the sinter layer height is similar to the cooling time, as shown in Fig. 8c. However, there is a negative correlation between the sinter layer height and the cooling device diameter. Obviously, the cooling device diameter dominates the result. Eqs. (23)-(25) are used to compute the pressure drop. Many parameters affect the pressure drop, but the sinter layer height and the cooling air normal superficial velocity are more important. Fig. 8d obviously shows that the trend of the pressure drop is similar to the sinter layer height. The pressure drop increases increasingly rapidly with the decrease in diameter, which is caused by the increase in cooling air normal superficial velocity.

\subsection{The influence of the sinter flow rate}

In this section, the considered parameters are the cooling air flow rate, the cooling time, the device height and the pressure drop. The difference is that the independent variables are the sinter flow rate and the cooling air temperature. The parameters are specified in Table 5 . The cooling air temperature varies from $20^{\circ} \mathrm{C}$ to $180^{\circ} \mathrm{C}$. The sinter flow rate is $300-500 \mathrm{t} / \mathrm{h}$.

As shown in Fig. 9a, the cooling air flow rate increases with the increase in sinter flow rate. The heat quantity removed by the cooling air increases with the increasing sinter flow rate. Therefore, a
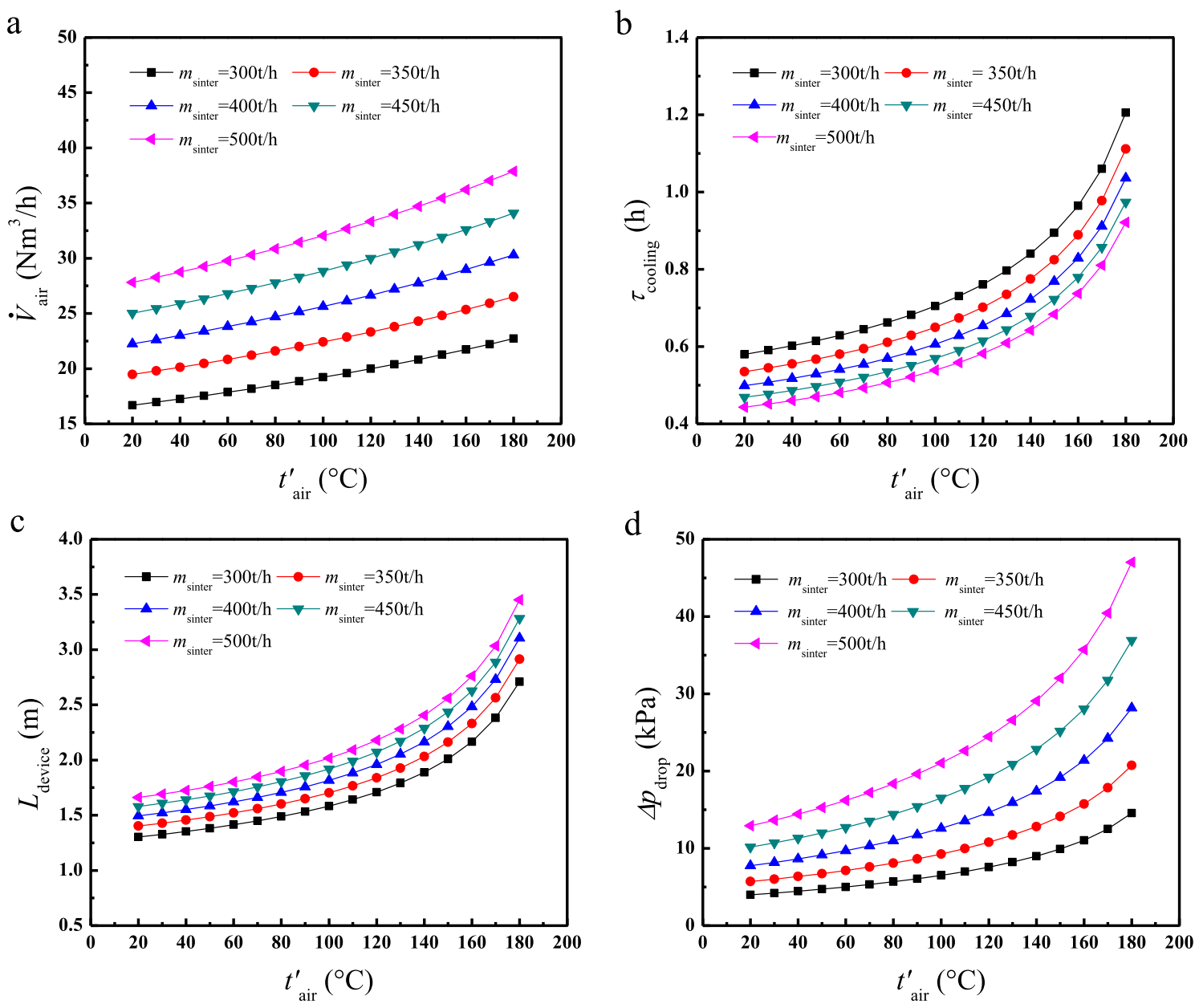

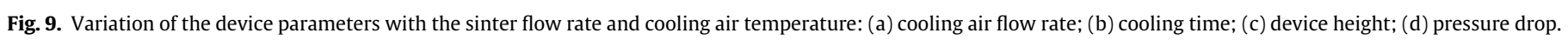


Table 6

Parameters for analyzing the hot sinter temperature effect.

\begin{tabular}{|c|c|c|c|c|c|c|c|}
\hline $\begin{array}{l}\text { Item } \\
\text { Unit }\end{array}$ & $\begin{array}{l}d_{\text {device }} \\
\mathrm{m}\end{array}$ & $\begin{array}{l}\eta_{\text {device }} \\
\%\end{array}$ & $\begin{array}{l}\dot{m}_{\text {sinter }} \\
\mathrm{t} / \mathrm{h}\end{array}$ & $\begin{array}{l}t_{\text {sinter }}^{\prime} \\
{ }^{\circ} \mathrm{C}\end{array}$ & $\begin{array}{l}t_{\text {sinter }}^{\prime \prime} \\
{ }^{\circ} \mathrm{C}\end{array}$ & $t_{\text {air }}^{\prime}$ & $t_{\text {air }}^{\prime \prime}$ \\
\hline Value & 10 & 95 & 400 & $650-800$ & 200 & $20-180$ & 600 \\
\hline
\end{tabular}

higher sinter flow rate corresponds to a higher cooling air flow rate. The high cooling air flow rate implies high normal superficial velocity and high convective heat transfer coefficient. Then, the sinter layer requires a shorter cooling time with a high sinter flow rate, which is obvious in Fig. 9b. The shorter cooling time helps reduce the sinter layer height, whereas the higher sinter flow rate makes the sinter layer height increase. Under the effect of the two factors (sinter flow rate and cooling time), the sinter layer height increases with the increasing sinter flow rate, as shown in Fig. 9c. This result illustrates that the mass flow rate has a stronger effect than the cooling time on the sinter layer height. As explained in the previous section, the sinter layer height and the cooling air normal superficial velocity affect the pressure drop. Therefore, the trend of the pressure drop is similar to the sinter layer height, as shown in Fig. 9d.

\subsection{Effect of the hot sinter temperature}

The temperature of the sinter that flows downwards from the sintering machine is commonly $750-800{ }^{\circ} \mathrm{C}$. However, some heat may be lost in the transport process in the improved technology. Because the newly built technological system can certainly reduce the loss, in this section, the hot sinter temperature and the cooling air temperature are used as independent variables. The parameters are specified in Table 6 . The hot sinter temperature is $650-800{ }^{\circ} \mathrm{C}$, while the cooling air temperature remains in the range of 20 $180^{\circ} \mathrm{C}$.

The heat quantity removed by the cooling air is determined by the sinter flow rate and hot sinter temperature and is positively correlated with the two factors. Therefore, the cooling air flow rate increases with the increase in hot sinter temperature, as shown in Fig. 10a. This analysis explains that a high cooling air flow rate helps reduce the cooling time. In this section, the hot sinter temperature is also an independent variable. As indicated in Eqs. (19) and (20), the hot sinter temperature plays a positive role in increasing the cooling time. However, the cooling air flow rate obviously dominates the trend of the cooling time. Consequently, the cooling time decreases with the increase in hot sinter temperature, as shown in Fig. 10b. As shown in Eq. (21), there is only independent variable: the cooling time. Then, the sinter layer height
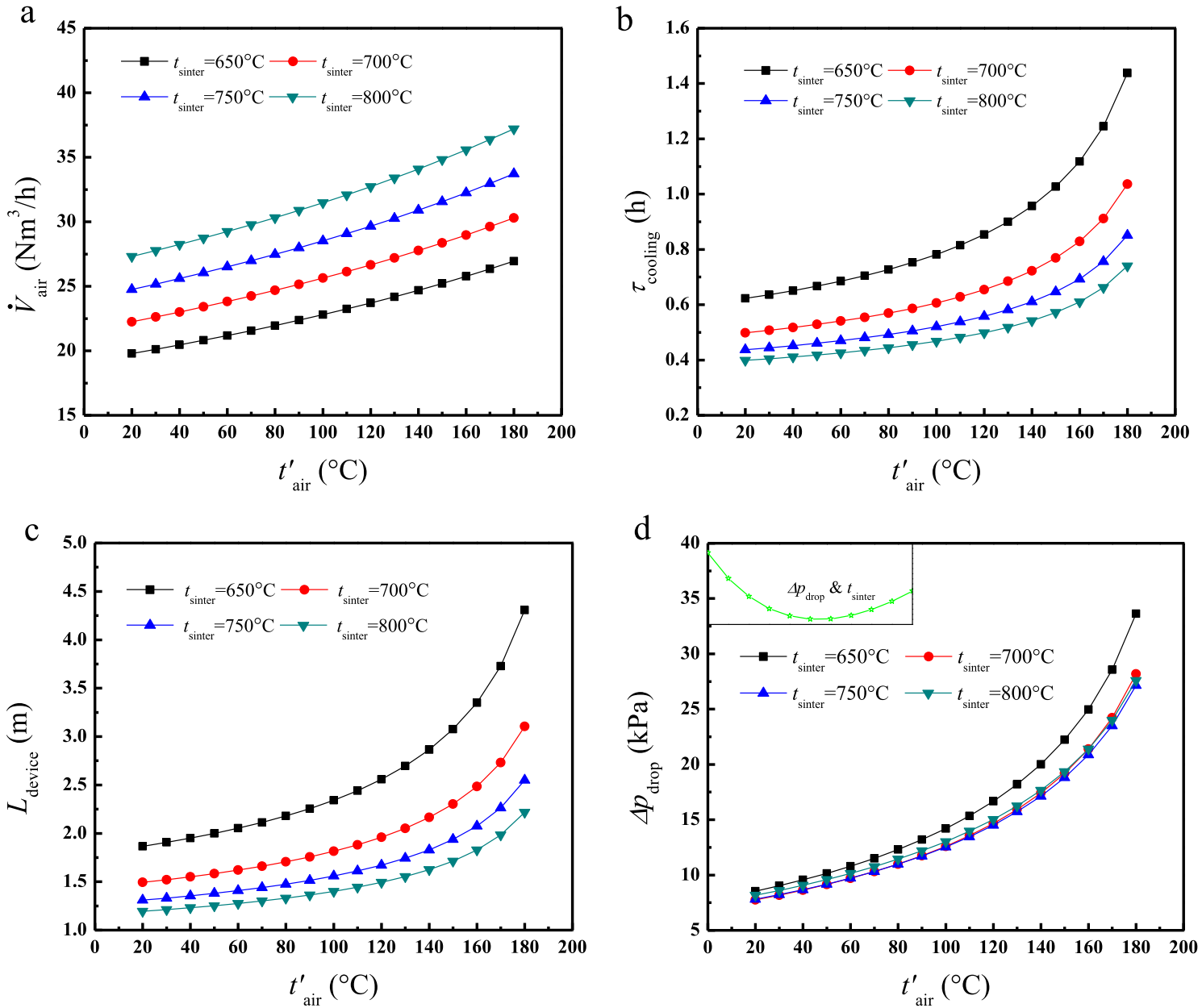

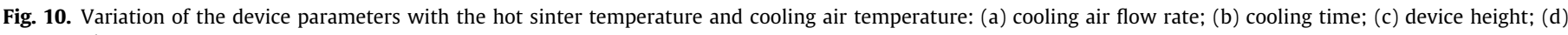
pressure drop. 
shows a nearly identical trend as the cooling time, as indicated in Fig. 10c. In Fig. 10d, the pressure drop increases with the increase in cooling air temperature. The pressure drop first decreases and subsequently increases with the hot sinter temperature. A detailed trend is also provided to show the variation of the pressure drop with the hot sinter temperature. Fig. 10d clearly shows that there is a minimum pressure drop. As explained above, the sinter layer height and the cooling air normal superficial velocity affect the pressure drop. For both parameters, high values lead to a high pressure drop. In this section, the two factors are consistent in strength. When the hot sinter temperature is low, the sinter layer height dominates the trend of the pressure drop, which decreases with the increasing hot sinter temperature. When the hot sinter temperature is high, the sinter cooling air normal superficial velocity dominates the trend of the pressure drop, which increases with the increasing hot sinter temperature.

\section{Conclusions}

In this article, a theoretical method is proposed to study the heat transfer and the flow process in vertical flow sinters. Several important parameters were analysed, namely, the cooling air flow rate, the cooling time, the device height and the pressure drop.

(1) Because of the inconstant properties of the sinter and the cooling air with temperature, the parameters trends are curve along the cooling device, such as the cooling air temperature and cooling air superficial velocity. The specific heat flux, the cooling air superficial velocity and the specific pressure drop increase along the cooling device. The specific cooling time is constant throughout the entire cooling device.

(2) When the cooling device diameter and the cooling air temperature are set as independent variables, the normal volumetric flow rate is not related to the cooling device diameter. The cooling time increases with the increase in cooling device diameter, whereas the sinter layer height has a negative correlation with the cooling device diameter.

(3) When the sinter flow rate is set as an independent variable instead of the cooling device diameter, the cooling time decreases, whereas the sinter layer height increases with the increasing sinter flow rate.

(4) Both cooling time and sinter layer height decrease with the increase in hot sinter temperature. It is important to note that the pressure drop has a minimum value that varies with the hot sinter temperature.

\section{Acknowledgements}

This work was supported by The National Key Research and Development Program of China (2016YFB0601401).

\section{References}

[1] A.C. Caputo, G. Cardarelli, P.M. Pelagagge, Analysis of heat recovery in gas-solid moving beds using a simulation approach, Appl. Therm. Eng. 16 (1) (1996) 8999.

[2] A.C. Caputo, P.M. Pelagagge, Heat recovery from moving cooling beds: transient modeling by dynamic simulation, Appl. Therm. Eng. 19 (1) (1999) $21-35$.

[3] X. Zhang, J. Zhang, C. Dai, D. Xie, Optimization and simulation of sinter cooling process, CIESC J. 62 (11) (2011) 3081-3087 (in Chinese).

[4] J. Leong, K. Jin, J. Shiau, T. Jeng, C. Tai, Effect of sinter layer porosity distribution on flow and temperature fields in a sinter cooler, Int. J. Miner., Metall. Mater. 16 (3) (2009) 265-272.

[5] J.Y. Jang, Y.W. Chiu, 3-D Transient conjugated heat transfer and fluid flow analysis for the cooling process of sintered bed, Appl. Therm. Eng. 29 (14-15) (2009) 2895-2903.

[6] H. Dong, L. Li, J.J. Cai, J. Li, Numerical simulation of heat exchange in vertical tank of waste heat recovery, J. North East. Univ. (Nat. Sci.) 33 (9) (2012) 12991302 (in Chinese).

[7] J.Y. Zhang, W.Y. Tian, C.H. Dai, X.H. Zhang, Simulation and optimization of sinter circular cooler layer-loading, CIESC J. 63 (5) (2012) 1385-1390 (in Chinese).

[8] J. Feng, H. Dong, Y. Zhao, Numerical investigation of gas flow in vertical tank for recovering Sinter waste heat, J. Northeast. Univ. (Nat. Sci.) 36 (5) (2015) 660664 (in Chinese).

[9] H. Dong, Y. Zhao, J.J. Cai, J.W. Zhou, G.Y. Ma, Leakage of Sintering-Cooling System, Iron and Steel. 47 (1) (2012) 95-99 (in Chinese).

[10] W.C. Qiao, Y. Peng, B. Cheng, et al., Sinter Furnace Cooling Device. Chinese Patent, CN201310127744.5, 2013-08-07 (in Chinese).

[11] H. Zhang, Design Manual for Sintering Process, Metallurgical Industry Press, Beijing, 2008 (in Chinese).

[12] S. Bao, W. Hou, J. Tong, An experimental study on sinter cooling and its waste heat recovery in Benxi Iron \& Steel Co., Energy Metall. Indus. 12 (6) (1993) 2023 (in Chinese).

[13] S. Yang, W. Tao, Heat Transfer (third version), Higher Education Press, Beijing, 1998.

[14] N. Wakao, S. Kaguei, Heat and Mass Transfer In Packed Beds, Gordon and Breach, Science Publishers, Inc, 1982.

[15] B. Liu, Y. Feng, Z. Jiang, X. Zhang, Heat and mass transfer in sintering process, CIESC J. 63 (5) (2012) 1344-1353 (in Chinese).

[16] N. Kong, Z. Wen, J. Feng, Q. Wang, D. Wang, H. Xia, L. Cheng, W. Wang, Y. Shen, Y. Zhang, Research status and development trend of the mathematical model for fluid flow and heat transfer process in the CDQ unit, Indus. Heat. 5 (2003) 1-6 (in Chinese).

[17] S. Ergun, Fluid flow through packed columns, Chem. Eng. Prog. 48 (2) (1952) 89-94. 